\title{
Where Have All the "Workers" Gone? A Critical Analysis of the Unrepresentativeness of Our Samples Relative to the Labor Market in the Industrial-Organizational Psychology Literature
}

\author{
Mindy E. Bergman and Vanessa A. Jean \\ Texas A\&M University
}

\begin{abstract}
In this article, we demonstrate that samples in the industrial and organizational (I-O) psychology literature do not reflect the labor market, overrepresenting core, salaried, managerial, professional, and executive employees while underrepresenting wage earners, low-and medium-skill first-line personnel, and contract workers. We describe how overrepresenting managers, professionals, and executives causes research about these other workers to be suspect. We describe several ways that this underrepresentation reduces the utility of the I-O literature and provide specific examples. We discuss why the I-O literature underrepresents these workers, how it contributes to the academic-practitioner gap, and what researchers can do to remedy the issue.
\end{abstract}

\section{Introduction}

It is our contention that the published industrial and organizational (I-O) psychology literature overrepresents salaried, core, managerial, professional, and executive employees and underrepresents wage earners, laborers, firstline personnel, freelancers, contract workers, and other workers outside managerial, professional, and executive positions, relative to the labor market in the United States and around the world. We further contend that this tendency is causing the organizational sciences to miss out on some important caveats to I-O theories, to misunderstand important phenomena, and to overlook phenomena that are defining experiences for many members of the labor market. In this article, we will demonstrate that workers are underrepresented in our published literature. Then, we will explain why we think this versity.

Mindy E. Bergman and Vanessa A. Jean, Department of Psychology, Texas A\&M Uni-

Correspondence concerning this article should be addressed to Mindy E. Bergman, Department of Psychology, Texas A\&M University, 4235 TAMU, College Station, TX 77843-4235. E-mail: mindybergman@tamu.edu 
is problematic for maximizing the utility of I-O theories and the I-O field by providing examples of critical domains in which worker experiences differ from manager, professional, and executive experiences. In the final sections of the article, we explicate some reasons why workers have been undersampled in the I-O psychology literature and make recommendations for some ways this can be remedied.

At the outset, it is important to note that this critique focuses squarely on the published literature in I-O psychology. Undoubtedly, there are many organizations that employ wage earners, low- and medium-skill workers, freelancers, contract workers, and other workers with nontraditional work arrangements and include them in their internal research. Our analysis focuses on problems in the recent/current state of the literature in I-O psychology, why this might be occurring, why this matters for the advancement of the science as a whole, how this might contribute to the academic-practice gap, and what we can do about it.

\section{Are Workers Really Underrepresented in the Published I-O Psychology Literature?}

Our first claim is this: Published research in I-O psychology has included samples of salaried, core, highly educated, highly skilled, managerial, professional, and executive employees at a disproportionally high rate and at the expense of other employees, including but not limited to wage earners, lowand medium-skill workers, freelancers, contract workers, and other workers with nontraditional work arrangements (Fair Labor Standards Act, 2011; Feldman, 1990; Hulin \& Glomb, 1999; Mintzberg, 1980). The "workers" in the title of this article are meant to reflect the latter list of people.

As we will show in this section, when considering the top I-O psychology journals, workers are underrepresented relative to their proportion of the labor market in the United States and around the world. Not only are manager, professional, and executive samples more common than either worker samples or their proportion of the labor market but also college student samples are considerably more common than are worker samples in the top I-O psychology journals (despite conventional wisdom about what research is accepted in our top journals; Dalal et al., 2010). To demonstrate this, we compared occupational population data with samples in some of the top I-O psychology journals. Note again that our argument is that the accumulated knowledge in I-O psychology journals does not reflect the labor market and that this is a problem for the development and utility of the I-O psychology literature. Undoubtedly, the practice of I-O psychology includes studies about and interventions aimed at workers, but these data do not regularly appear in I-O journals. 


\section{U.S. Labor Market Data}

The Bureau of Labor Statistics (BLS) tracks employment in the United States. BLS data for May 2014 showed that the 10 largest (out of 821) detailed occupations in the United States at the time were all nonmanagerial: (a) retail salespersons; (b) cashiers; (c) food preparation and serving (including fast food); (d) office clerks (general); (e) registered nurses; (f) customer service representatives; (g) waitstaff; (h) laborers and freight, stock, and material movers who move material by hand; (i) secretaries and administrative assistants (except legal, medical, and executive); and ( $\mathrm{j}$ ) janitors and cleaners (except maids and housekeeping cleaners; BLS, 2015a). Together, these 10 detailed occupations accounted for over 28 million employed persons in the United States, or $21 \%$ of the approximately 135.1 million total employed persons in the United States (BLS, 2015a). Turning to the 22 major occupational groups tracked by the BLS, the largest were office and administrative support (21.6 million employed persons; $16 \%$ of total employed persons in the United States), sales and related (14.2 million; 10.5\%), food preparation and service related (12.3 million; 9.1\%), production ( 8.9 million; $6.6 \%$ ), and transportation (9.2 million; 6.8\%). In contrast, all management occupations totaled roughly 6.7 million employed persons (5.0\%), whereas all business and financial occupations were just over 6.8 million (5.0\%; BLS, 2015a).

\section{International Labor Market Data}

World-statistics.org, a public clearinghouse of national census and international organization databases (e.g., United Nations, European Union, World Bank), provides a summary of occupational data for 35 nations (World Statistics, n.d.) based on the United Nation's International Labour Organization (ILO, 2014) categories $^{1}$ (International Standard Classification of Occupations-1988). On the basis of these databases, world-statistics.org reports that, in 2012 and of the 35 represented nations, Luxembourg

1 The ILO assigns employed persons into 10 general categories via their Key Indicators of the Labour Market capitalized as the title of a measure (International Standard Classification of Occupations-1988), eight of which are classified via skill and educational requirements. According to the ILO, two categories (professionals; technicians and associate professionals) require high skills and at least some college-level education, and six categories (clerks; service workers and shop and market sales workers; skilled agricultural and fishery workers; craft and related trades workers; plant and machine operators and assemblers; elementary occupations) do not (ILO, 2014). The ILO did not assign skill levels to the legislators, senior officials, and managers category, but we judged that it likely requires high levels of skill and education. The ILO also did not assign skill levels to the armed forces category; this category likely includes employees of varying skill and education levels (e.g., low ranks vs. high ranks; enlisted vs. officers). We did not classify the armed forces category in our analyses, so employees make up the remainder of the employed persons. Note, however, that the armed forces have more enlisted (i.e., worker) than officer (i.e., manager, professional, and executive) personnel. 
had the highest proportion of employees holding positions categorized as professionals, legislators, senior officials, managers, technicians, and associate professionals (which aligns with our professional/managerial/executive category), with $57.2 \%$ of the employed population; clerks, service workers, shop and market sales workers, skilled agricultural and fishery workers, craft and related trades workers, plant and machine operators, assemblers, and elementary occupations (which we will loosely align with our worker category) together accounted for $41.2 \%$ in Luxembourg at the same time (World Statistics, n.d.). At the other extreme, Cambodia had the smallest percentage of professionals/managers (3.6\%) of employed persons, and the worker group accounted for $93.3 \%$ of employment.

Another source of world labor market data is the Organisation for Economic Co-operation and Development (OECD), an assemblage "where the governments of 34 democracies with market economies work with each other, as well as with more than 70 nonmember economies to promote economic growth, prosperity, and sustainable development" (OECD, n.d). According to OECD, in 2013 the percentage of employed persons who were in temporary employment ${ }^{2}$ ranged from $1.5 \%$ in Romania to $29.7 \%$ in Chile, with an average for OECD member countries of $11.8 \%$; G7 countries averaged 9.2\%, whereas the 28 European Union countries averaged 14.0\%. Temporary employment data were not reported for the United States. In 2013, the percentage of employed persons who were in self-employment ${ }^{3}$ ranged from $6.6 \%$ (United States) to $35.9 \%$ (Turkey) and an extreme outlier of $52.6 \%$ (Colombia). Finally, the percentage of employed persons in part-time employment ${ }^{4}$ in 2013 ranged from Bulgaria $(2.1 \%)$ to Switzerland $(26.4 \%)$ and the Netherlands (38.7\%), with the OECD average at $16.8 \%$; the United States came in at $12.3 \%$, the G7 at $17.4 \%$, and the European Union at $17.5 \%$.

2 OECD defined temporary employment as "wage and salary workers whose job has a pre-determined termination date. National definitions broadly conform to this generic definition, but may vary depending on national circumstances" (https://data.oecd.org/emp/temporary-employment.htm\#indicator-chart).

3 OECD defined self-employment as "the employment of employers, workers who work for themselves, members of producers' co-operatives, and unpaid family workers. The latter are unpaid in the sense that they lack a formal contract to receive a fixed amount of income at regular intervals, but they share in the income generated by the enterprise. Unpaid family workers are particularly important in farming and retail trade. All persons who work in corporate enterprises, including company directors, are considered to be employees. Self-employment may be seen either as a survival strategy for those who cannot find any other means of earning an income or as evidence of entrepreneurial spirit and a desire to be one's own boss" (https://data.oecd.org/emp/self-employment-rate.htm\#indicator-chart). Notably, self-employment does not have to be full time.

4 OECD defined part-time employment as "people in employment (whether employees or self-employed) who usually work less than 30 hours per week in their main job" (https://data.oecd.org/emp/part-time-employment-rate.htm\#indicator-chart). 


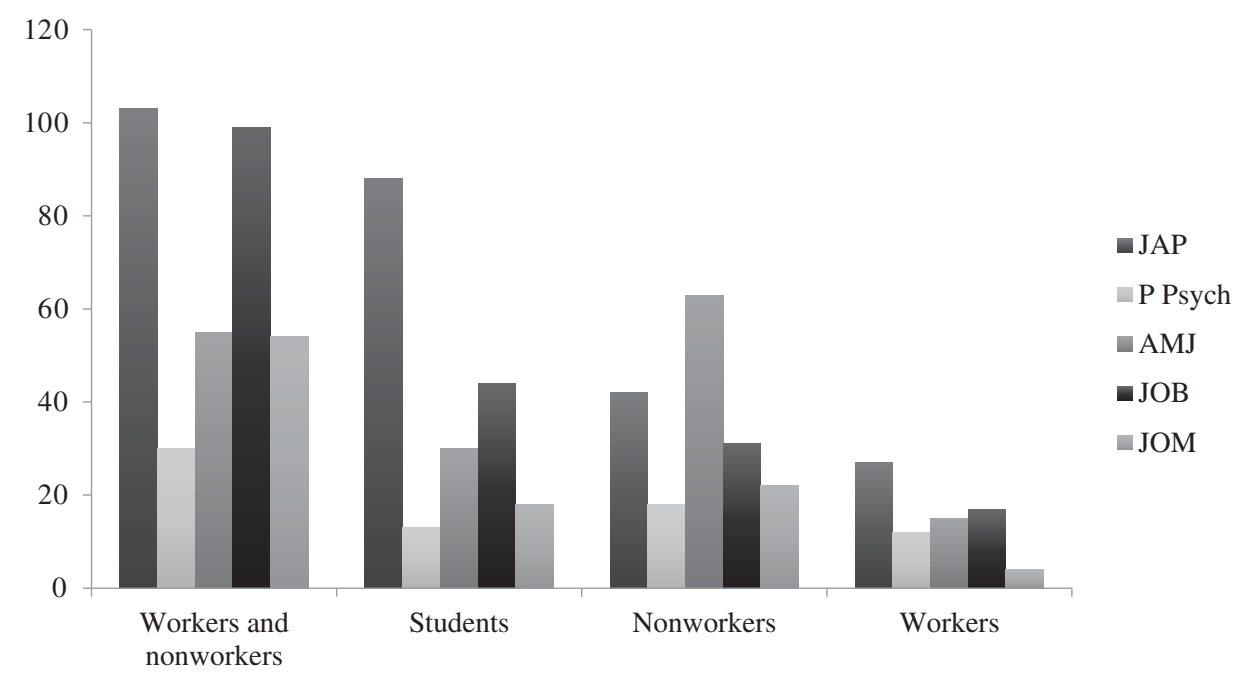

Figure 1. Samples from five top industrial-organizational journals (2012-2014), classified by worker status. JAP = Journal of Applied Psychology; P Psych = Personnel Psychology; AMJ = Academy of Management Journal; JOB = Journal of Organizational Behavior; JOM = Journal of Management.

\section{Samples in I-O Psychology Journals}

In contrast, we reviewed all articles published in 2012-2014 in five consensus top journals that are meant to be broad topic journals: Journal of Applied Psychology, Personnel Psychology, Academy of Management Journal, Journal of Management, and Journal of Organizational Behavior. Using the descriptions of samples in the methods sections, we coded for the occupation of participants relative to our descriptions of workers versus managers/executives/professionals. After excluding meta-analyses and articles with simulated or organizational-level data $(N=321)$, there were 811 studies/separate samples (i.e., some articles contained multiple studies; some studies contained several distinct samples). Of the 811 samples (see Figure 1), 24\% were student samples, ${ }^{5}$ and $22 \%$ included managers and/or professionals only. Three hundred and forty-one (42\%) studies (a) clearly included workers and others in their samples (e.g., all members of a bank branch, from teller to president) or (b) described broad samples that cut across occupational categories, such as Internet panels (e.g., StudyResponse, Mechanical Turk), national samples, people waiting for jury duty, and twin

5 The problem of overreliance on undergraduate student samples in psychology has been discussed extensively in the psychology literature (Henrich, Heine, \& Norenzayan, 2010; Henry, 2008; Sears, 1986), although others have made counterpoints (e.g., Ilgen, 1985). Thus, we focus on the problem of the representation of workers relative to managers, professionals, and executives rather than students. However, it is worth noting that undergraduate students are likely to become managers, professionals, and executives. 
studies. In this latter category, it is impossible to be certain of any work status because the methods sections usually include descriptions of industries but not the position within the industry (e.g., "food services" or "retail" without indicating whether the participant was a manager or a frontline worker). However, it seemed reasonable to conclude that workers were present in these samples. Finally, only 75 samples (9\%) focused specifically on workers - that is, people (a) who were not executive, professional, or managerial employees, and/or (b) who were low- to medium-skill, and/or (c) who were wage earners rather than salaried. These samples included call center workers, frontline sales workers, utility workers, retail sales workers, stockers, laborers, nurses, and U.S. military service members. None $(0 \%)$ of the studies explicitly examined freelancers, contractors, or the like.

An ongoing interest in leadership notwithstanding, this distribution of samples is not representative of the population of workers in the United States or elsewhere in the world. Thus, our first contention-that workers are underrepresented in our samples compared with their presence in the workforce-is supported. We now turn to our second contention-that this is a problem for the development of the scientific knowledge in I-O psychology.

Why Does Underrepresentation of Workers Negatively Affect Our Science?

Our second claim is this: The underrepresentation of workers causes us, as a science, to fail to fully understand our phenomena of interest. In this section, we use the lens of cultural psychology and critical psychology theories to explain why this happens.

Generally, the overreliance on some kinds of employees over othersregardless of their representativeness of the labor market-creates an inaccurate picture of workplace experiences. There could be phenomena that are not examined at all, important moderators that are overlooked, or a misrepresentation of the commonality of some effects. Thus, some of these concerns would still exist if the reverse were the case-that is, that workers were disproportionally represented in our literature to the detriment of sampling managers, professionals, and executives. However, this problem is of greater concern when the smaller segment of the labor market (i.e., managers, professionals, executives; undergraduate students who are likely to become managers, professionals, and executives) is the larger segment of the scientific literature, because what is common in the literature is uncommon in the labor force (and vice versa). This reduces the utility of the published literature to organizations, possibly contributing to the academic-practice gap in our field.

Critical writings from the field of cultural psychology explain that the experiences of the groups who are studied within a field become 
normalized and are assumed to generalize to other groups without the explicit testing of external validity (Adams \& Salter, 2011; Henrich, Heine, \& Norenzayan, 2010; Salter \& Adams, 2013; Sue, 1999). For example, an effect that is found in a sample of managers, professionals, or executives would be assumed to generalize to a sample of workers, without explicitly testing this assumption. This assumption has two clear effects. First, because it is assumed that it is unnecessary to test this effect in other groups, constructive replication within other samples is discouraged, and differences (when they exist) are not discovered. Second, on the rare occasion when the effect is tested in other groups, the initial group becomes the standard against which all other samples are compared; when differences are discovered, researchers are expected to justify differences between the results from "new" samples when they diverge from "old" samples, but this justification expectation is unidirectional-that is, the lens is rarely turned to understand why "old" samples differ from the "new" ones (Adams \& Salter, 2011; Fox, Prilleltensky, \& Austin, 2009; Salter \& Adams, 2013). So, if an effect that has been supported for managers, professionals, and executives was found to be different for workers, then the effect would be explained as how workers are "different" rather than discussed as how workers and managers/professionals/executives differ from each other and what factors produce these differences. As a result, the phenomenology of managers, professionals, and executives becomes "normal"; the use of any other type of sample has to be justified; and the use of managers, professionals, and executives as samples is unquestioned (Adams \& Salter, 2011; Fox et al., 2009; Salter \& Adams, 2013). There is little critical examination-at the level of the science or at the level of individual articles-regarding why these samples of managers, professionals, and executives were used. If results from worker samples differ from those of previous studies on managers, professionals, and executives, then workers will be (a) "othered" (i.e., treated as different or alien; Canales, 2000; Weis, 1995) and (b) pathologized (i.e., different is equated to bad; Weis, 1995), and the new results will be discounted (i.e., there must be something wrong with this study because it fails to support previous findings; Weis, 1995).

Because psychology in general is focused on individual-level phenomena (and, to a lesser extent, multilevel phenomena in which individuallevel phenomena are one of the levels), othering, discounting, and pathologizing are particularly likely because the structural factors that create differences between groups are not the primary focus of our science. The differences between groups are perceived through the lens of essentialism (i.e., due to the inherent nature of the people themselves rather than due to an environmental dependency such as structural factors that operate on the people; Bohan, 1993; Harris, 1990). Of course, there are individual 
differences between managers, professionals, and executives and workers (Hunter, 1986), but there are also environmental factors that create some of these differences; as a psychological science, we focus more on the individual differences themselves rather than on their environmental causes. Greater attention to these environmental factors could contribute to better understanding of worker status in the workplace.

Our larger point is simple: When I-O psychology fails to study the full range of the labor market, it is likely that the field is not fully articulating the nomological network surrounding a construct of interest. Suboptimal conclusions will be reached about phenomena of interest, reducing the overall utility of the I-O literature. This has further implications when considering the impact of I-O psychology in the service of organizational functioning and society at large. The failure to sufficiently sample workers might cause I-O researchers to incorrectly weight the importance of some issues relative to their impact in organizations because recognizing the importance of such issues might be linked to the proportion of people we study-rather than the proportion of people in the real world (Tversky \& Kahneman, 1973) who are dealing with these problems. This could minimize the impact the I-O discipline has on psychological sciences as a whole, organizations, and society, relegating I-O psychology to the fringe.

We are not alone in concerns about the relevance of I-O psychology to other parts of psychology and other sciences as well as to organizations and society (e.g., Allen, 2013; Reynolds, 2012; Rotchford \& Roberts, 1982; Ryan \& Ford, 2010). We are not suggesting that merely changing who is sampled in I-O studies will suddenly make I-O psychology the darling of the psychological sciences or the go-to brand for organizations. But we are suggesting that recognizing that I-O psychology has understudied the largest proportion of the workforce and that aiming to do something about that might increase the relevance of I-O psychology to the broader psychological sciences and to organizations and might address some of the academic-practitioner gap. Providing more academic knowledge about more people and more problems can only result in greater relevance to organizations and society as a whole.

In sum, we see the issue of nonrepresentative sampling of the workforce in the I-O psychology literature as having several effects on I-O psychology as a science. First, by not adequately covering the total range of workers, important boundary conditions in our current theories could be missed. Second, important research questions that are relevant to some segments of the workforce are overlooked. Third, the ability to improve conditions for people in organizations is reduced because efforts are concentrated in ranks that are less populated. Fourth, the ability to improve organizational functioning is not maximized because attention is paid to only some segments of the organization. Finally, the accepted paradigms in I-O are framed around the 
experiences of a particular and relatively uncommon subset of the workforce rather than the vast majority of employees in the labor market, which could hamper the ability of I-O as a science to move forward and to contribute to society.

\section{How Does Underrepresentation of Workers Affect Our Science?}

In this section, we articulate four different modes through which the underrepresentation of workers undermines the utility of our published science, with an example for each. These include overlooked phenomena, gamma change of constructs, worker status as a moderator, and effects of other human capital patterns linked to worker status. This list is not meant to be exhaustive, but we believe that they represent major concerns about how undersampling workers negatively affects the I-O psychology literature.

It is important to note that we do not believe that worker status will affect every process and nomological net and limit the generalizability of all scientific endeavors to date. Undoubtedly, many workplace experiences are similar for workers and for managers, professionals, and executives; theory can generalize even when specifics do not. As an example, we anticipate that the principles of many withdrawal models will hold across all employees in general (Hulin, 1991; Lee \& Mitchell, 1994; P. C. Smith, Kendall, \& Hulin, 1969; Thibaut \& Kelley, 1959), even though there are likely to be differences in frequency of alternative opportunities or in how particular factors (e.g., increases in pay vs. increases in challenge or autonomy) are weighed in turnover decisions. As another example, we expect that the effects of surface acting and deep acting on employee well-being are likely to be the same across employees (e.g., Beal, Trougakos, Weiss, \& Green, 2006; KammeyerMueller et al., 2013), but again the context, frequency, and expectations to engage in emotional labor are likely to differ across worker status.

Further, there are domains in which worker status is already known to be an important moderator. For example, Campbell's (1990) description of the law of the effect of general mental ability on work performance includes a moderator that is linked to worker status such that the relationship between general mental ability and work performance is expected to be stronger in jobs that require more information processing-that is, managers, professionals, and executives (Hunter, 1986). Thus, we turn now to the four ways that our published literature suffers from the underrepresentation of workers.

\section{Overlooking Workplace Phenomena That Happen to Workers}

One of the most obvious problems with failing to study workers in the I-O literature is that important workplace phenomena that are disproportionately or exclusively experienced among workers could be overlooked. 
For example, lower income families are more likely to experience food insufficiency, which in turn has an effect on children's academic performance (Alaimo, Olson, \& Frongillo, 2001). Such phenomena are considerably rarer for employees with higher socioeconomic status (SES). Notably, it is difficult if not impossible to study such phenomena-either as academics or in practice-without the open-ended input of workers precisely because these experiences are rare for managers, professionals, and executives. Because managers, professionals, and executives are considerably less likely to be exposed to the phenomena that occur primarily among workers, they are also less likely to study them.

Example of overlooked phenomenon: Economic tenuousness. One of the most obvious differences between many workers and managers, professionals, and executives is economic tenuousness. We use the term economic tenuousness to mean that the person has relatively low (a) total money available for use and/or (b) consistency of money flow. Some of this is structural, built into the relationship between employer and some employees. Freelancers, for example, have a clearly tenuous relationship with the organization and, consequently, with monetary intake because freelancing is typically project based. When the project ends, there is no guarantee that another project will come along. Further, some freelancing is completed on "spec" such that the work is done in advance of securing a contract with the organization (e.g., features writing for magazines); if the work is considered worthy, it is then purchased by the organization. Although this type of fleeting interaction with the organization is not common in most employment relationships, it is more common than would be expected based on the sampling seen in our journals (i.e., $0 \%$ unless part of a broad sample).

But economic tenuousness is also part of the experience of many workers who are core employees, even full-time workers. In particular, wage earners are at risk for economic tenuousness, not because of a fragile or temporary relationship with the organization but rather because of the cost to the individual of not completing a full day's work. On average, workers make less money per year than do managers, professionals, and executives. For example, the median weekly earnings in 2013 for managers, professionals, and related occupations was $\$ 1,132$, compared with $\$ 493$ for service occupations (BLS, 2013). Although this is clearly structural, such that organizations choose to pay people based on their position and their skills, the incidental effect is that workers are more likely to be impoverished than are managers, professionals, and executives.

For salaried workers, there are paid vacation days and paid sick days that excuse the worker from work yet still preserve the whole salary. Further, in many organizations, salaried workers can arrive late (or depart early) without penalty, but this is not true for many wage earners. Any hour not worked 
is an hourly wage unearned. The workers' presence at the job is accounted for in a strict, monetary sense; workers are required to officially mark their time at the organization to ensure fair pay (on both sides of the transaction). Further, workers who are paid hourly are often subjected to draconian tardiness and absence policies, which could cause a worker to lose a job. Thus, missing work means losing pay if not a livelihood. Note that lost wages from even a 2-day period in the typical month (approximately 22 working days, assuming a 5-day work week-which might not be a good assumption for many workers) is a loss of $9 \%$ of the month's pay; lost wages from a week is nearly $25 \%$ of the month's pay. For lower income households, such losses can be devastating.

Despite news media attention to economic tenuousness (e.g., homelessness, bankruptcy), little of the I-O literature addresses the experience of economic tenuousness. Few studies examine the effects of lost wages, total wealth, or other economic indicators as important factors in workplace experiences or the work-nonwork boundary. Yet when economic tenuousness is studied, it is clearly influential. For example, people who are in economically tenuous situations are more likely to engage in presenteeism when they are sick (Aronsson \& Gustafsson, 2005; Aronsson, Gustafsson, \& Dallner, 2000), probably because they cannot afford the lost wages. Economic tenuousness has also been linked to the concept of job insecurity (Ashford, Lee, \& Bobko, 1989; Berglund, Furaker, \& Vulkan, 2014; Probst, 2000). The sexual harassment literature has theorized that economic dependence on jobs makes women more likely to be sexually harassed and less likely to report it (Fitzgerald, Hulin, \& Drasgow, 1995).

Relatedly, little research in I-O psychology focuses on second jobs (for exceptions, see Feldman, 1990; Jamal, Baba, \& Riviére, 1998; Zickar, Gibby, \& Jenny, 2004). Second jobs are one way for people to shore up their economic situation, although it also increases some costs (e.g., transportation, childcare) and exacerbates some problems (e.g., work-life balance). Although it is likely that published samples have included people who hold second jobs, research generally does not include this variable and its impact on any constructs and processes related to their "first" job (e.g., how does having a second job affect performance on the first job?). In fact, Boyd and Sliter (2014) recently called for more research on multiple-job holders because (a) so little is known about these experiences and because (b) so many people hold multiple jobs.

In sum, the economic tenuousness of workers is likely to be significantly higher than that for managers, professionals, and executives, although there are bound to be workers who do not experience economic tenuousness and managers, professionals, and executives who do. We have described why economic tenuousness, in and of itself, should be of interest to I-O psychology 
as well as why it could be an important predictor or moderator in other theories. Continuing to overlook this phenomenon-as well as others that occur primarily among workers-creates an impoverished knowledge base about the largest part of the labor market.

\section{Differences in Construct Meaning Across Worker Status}

Another way in which underrepresentation of workers affects our published science is that some constructs could have different meanings across the labor market. For example, what is a "career ladder" to an electrician? What is a "stretch assignment" for a janitor? Although it might be the case thatparallel to the previous example-some experiences that occur among managers, professionals, and executives are unlikely to occur among workers (such as stretch assignments and career ladders), when researchers deploy surveys to an entire organization to measure these nonworker constructs, the resulting data cannot be interpreted consistently across worker status. In essence, we are suggesting that there can be gamma change in some constructs across worker status (Dowling, 2001; Howard, Mattacola, Howell, \& Lattermann, 2011). This is important not only from a measurement perspective but also from a nomological net perspective. The causes, correlates, and consequences of these essentially different constructs could be very different. Thus, understanding whether a construct is consistent across worker status is a first step in investigating the nomological network and phenomenology of experiences of workers.

Example of different construct meaning: Flexibility. Flexibility is an example of a variable that is likely to be understood and experienced differently for workers and other employees. Managers, professionals, and executives are likely to have more control over and less variability in their work hours than workers do (McMenamen, 2007). Although workers are less likely to have a standard set of hours than are managers, professionals, and executives (Johnson \& Lipscomb, 2006), this seemingly flexible schedule is often at the beck and call of the employer rather than a benefit that serves the employee's purposes; this latter idea of benefit is how flexibility is typically conceptualized in the literature (Hill, Erickson, Holmes, \& Ferris, 2010; Scandura \& Lankau, 1997; cf. Shockley \& Allen, 2007). In other words, workers have irregular schedules, not flexible schedules.

As an example, consider a fast food worker who arrives at work at her scheduled work time. Her work hours might differ from day to day, but this likely benefits her supervisor and organization and fulfills staffing needs more than it benefits the employee herself. (This is not to suggest that workers can never request time off or a different schedule to meet personal needs.) Further, if the restaurant is not busy, she may be sent home, losing a portion of her anticipated income. As an hourly worker, she can also have her 
start time changed with little notice, such as a call from a supervisor changing a start time from 10 a.m. to noon if business is slow that morning. The damaging effects of such practices to the employee's pay are multiplied if the employee has already arranged for childcare during those hours. In contrast, salaried employees are less likely to have to clock in and out of the workplace and usually have paid personal time off hours (or, at least, personal time off that does not put the employee at risk for losing the job). Being sent home early from work because it is a slow day does not reduce the pay for a salaried employee; instead, it is like a gift of nonwork time rather than a burden that threatens their livelihood.

Recent studies-outside of I-O psychology-on flexibility for lowincome workers demonstrate this distinction and its effect in the lives of workers. Lambert, Haley-Lock, and Henly (2012) found that reduced working hours and varying work schedules disadvantaged low-income workers because these forms of flexibility, which are commonly thought of as beneficial to employees, lead to wage instability for workers. Further, a qualitative study of low-income women in the United States found that scheduling flexibility for these workers meant experiencing the following four problematic issues: erratic work schedules, not enough working hours, time theft (e.g., forced off-the-clock work or the employer avoiding overtime pay via mandatory long breaks or lunches), and the reduction of working hours as a punishment or means of controlling workers (Jacobs \& Padavic, 2014). Finally, even when autonomous, beneficial schedule flexibility is available for low-income workers, other aspects of working are higher priorities, such as working as many hours as possible to increase income (Williams, 2006).

In sum, even though there is evidence outside of I-O psychology that flexibility is nonautonomous and economically threatening to low-income workers, I-O research has largely overlooked the differences between work schedule flexibility for low-income, hourly workers and work schedule flexibility for salaried/professional workers. This could be because flexibility is defined and studied in ways that look at the experiences of salaried workers for whom flextime and/or flexplace are possible (Scandura \& Lankau, 1997; Shockley \& Allen, 2007). It is perhaps time to develop a new construct that accounts for flexibility that benefits employers rather than employees and to acknowledge that the current framing of flexibility in the literature only applies to salaried/core professional workers who benefit from autonomous flexibility.

\section{Worker Status as a Moderator}

Worker status could influence the extent to which an employee endorses a particular attitude, experiences particular events (e.g., frequency or severity), or engages in behavior; this could ultimately result in worker status moderating relationships between key variables. In this case, both workers 
and managers, professionals, and executives have a particular experience, and the particular experience has the same meaning to both groups, but the groups significantly differ in the extent to which the experience occurs or the extent to which two variables are related. As a prime example, Campbell's (1990) description of the law of the effect of general mental ability on work performance includes a moderator that is linked to worker status such that the relationship between general mental ability and work performance is expected to be stronger in jobs that require more information processing (e.g., Hunter, 1986). As another example, there is a robust phenomenon that job satisfaction is positively correlated with position in the organizational hierarchy such that those workers on the front line tend to have lower job satisfaction than organizational members in the C-suite do (Robie, Ryan, Schmieder, Parra, \& Smith, 1998). Below, we discuss safety as an example of this problem.

Example of worker status as a moderator: Safety. Safety is an example of how worker status could moderate the relationships among variables or influence the mean levels of a variable across organizational members. Undoubtedly, workers are at greater risk for serious injury than are managers, professionals, and executives; although there are workers who are as unlikely to meet with serious injury as managers, professionals, and executives (e.g., administrative assistants, call center employees), there are few managers, professionals, and executives who are as at risk as workers (e.g., construction, meat processing, road construction). For example, in 2013, there were 4,585 workplace fatalities in the United States. The deadliest jobs that year (per full-time worker equivalent) were (in order from most deadly to 10th most deadly) logging workers; fishers and related fishing workers; aircraft pilots and flight engineers; roofers; refuse and recyclable material collectors; mining machine operators; driver/sales workers and truck drivers; farmers, ranchers, and other agricultural managers; electrical power-line installers and repairers; and construction laborers (Dill, 2014). Most of these are worker occupations, not managerial, professional, or executive positions. Further, it is clear that the causes of worker deaths are more likely to be related to the work itself (e.g., contact with hazardous conditions) than to incidental events in the workplace (e.g., transportation fatalities), while the reverse is true for managers, professionals, and executives. Table 1 provides some examples from the BLS (2015b) showing the causes of workplace death for a subset of occupations (see http://www.bls.gov/iif/oshwc/cfoi/cftb0281.pdf for the full chart; note that work-related transportation deaths are not incidental for transportation workers, whereas they are incidental for managers; that is, transportation is the actual job of truck drivers but not for managers.) 


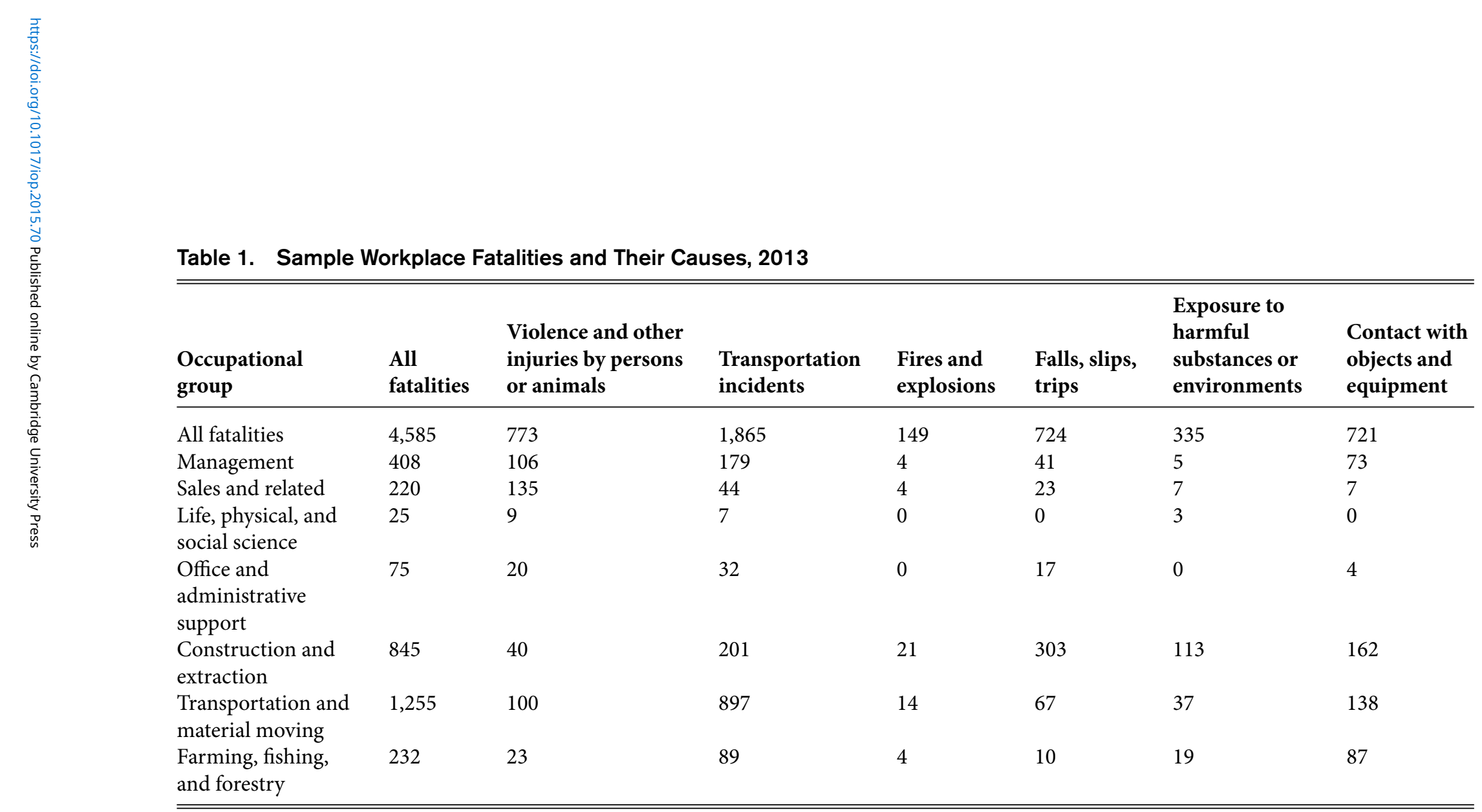

Note. Examples extracted from Bureau of Labor Statistics information; rows do not sum to "All fatalities" row in sample information provided here. Complete information can be found at http://www.bls.gov/iif/oshwc/cfoi/cftb0281.pdf 
These differences in rates and causes of fatalities are indicative of the bifurcation between managers, professionals, and executives and workers regarding perceptions of workplace safety. Two concepts within the safety literature are relevant here: safety climate and work hazards. Safety climate is the shared perceptions of the policies, procedures, and practices related to safety in the workplace (Zohar, 2010, 2014). Work hazards are the various risks to safety and well-being that employees encounter (Cox \& Cox, 1993). Research has shown that perceptions of safety climate differ by employee level, with employees higher in the organizational hierarchy having more positive views of the safety climate (Beus, Jarrett, Bergman, \& Payne, 2010; Cheyne, Tomas, Cox, \& Oliver, 2003; Harvey, Bolam, \& Gregory, 1999). Similarly, employees who are lower in the organizational hierarchy perceive more workplace hazards than do employees above them (Cheyne et al., 2003) and are exposed to greater numbers of hazards (Adler \& Rehkopf, 2008; BLS, 2015b). Together, these findings indicate a disconnect between managers, professionals, and executives and workers on safety climate and workplace hazards.

These issues are important both practically and theoretically. Although some workers do get promoted to the lower rungs of management (e.g., foreperson, supervisor) and occasionally higher, many employees who entered the workplace with a 4-year college education and who are on the managerial or professional track are unlikely to have had worker jobs in the same company (Gulf Research Program, 2014; National Science Board, 2012). For example, engineers in chemical processing plants are unlikely to have worked as operators or in medium-skilled process maintenance in chemical facilities. Thus, the decisions made by managers, professionals, and executives might not be informed by the true situation "on the ground" because they have an idealized vision of safety in the workplace. That is, they might perceive safety as it should be, not how it is. Even when managers, professionals, and executives observe conditions on the ground, they might not get a true picture of the real conditions because workers might change their behavior when being observed by members of the leadership team (Landsberger, 1958). Further, although many managers, professionals, and executives will have more academic knowledge about workplace hazards the organization faces, they are less likely to have experience with how the workplace processes unfold in real time and among real people, with managerial pressures, teamwork issues, and the like.

Therefore, it is imperative that workers' experiences of safety at work are understood and included in decision-making processes and that workers are involved in the development of safety procedures and the implementation of safety policies that ultimately impact safety climate. Such collaboration should lead to a more cohesive safety climate and more positive safety 
outcomes. Further, it matters who is sampled for a safety climate survey when trying to predict safety-related outcomes. Surveying the wrong level of personnel (or only one level of personnel) could lead to weaker predictive ability, which would undersell the value of safety climate both empirically and practically. In addition, there might be important questions about safety climate that are not being asked of workers because managers, professionals, and executives have greater control over the content of safety climate surveys. This could again lead to substandard understandings of safety climate and indicate suboptimal change levers for improving safety climate.

In sum, it is clear that workers and managers, professionals, and executives differ in their perceptions of safety climate and workplace hazards. This is likely to be important to an understanding of safety-related outcomes as well as the decisions that are made in organizations around safety. Considering the drastic consequences of poor decisions in many safety-critical situations (e.g., chemical spills or environmental releases; fires; explosions; crashes), making sure that workers are included in safety research is essential to the well-being of all employees and their families, civilians in the surrounding areas, and even the natural environment.

\section{Human Capital Patterns Associated With Worker Status}

Finally, there are human capital patterns in the labor market that influence experiences across worker status. These human capital patterns are often purposefully and appropriately related to organizational and occupational positions. For example, workers are generally less educated than are managers, professionals, and executives because of the different requirements for their jobs. However, there are other human capital patterns associated with organizational and occupational positions that are incidentally related to worker status. Some of these occur because of nonspurious correlations with job requirements (e.g., lower educational attainment for people from poorer families of origin and the confluence of poverty and race), whereas others occur because particular work arrangements are more attractive to some segments of the labor market (Harrington, 1994). Although we completely agree that job requirements to become managers, professionals, and executives should be honored so long as they are job related, it is folly to pretend that these human capital differences do not matter. Human capital factors have profound effects on people's lives beyond the occupational positions they hold, and the factors outside of the workplace also influence experiences inside the workplace.

Example of human capital patterns: Health. Health is an example of a factor in human capital patterns that is related to and reciprocal with worker status. Social and physical settings (including a person's work, home, and neighborhood) differ by SES and impact individuals' contact with 
health-damaging conditions as well as health-protecting resources (Adler \& Rehkopf, 2008). A long, rich literature on the relationship between SES and illness indicates that poorer people have worse health than do richer people (Brooks-Gunn \& Duncan, 1997; Pritchett \& Summers, 1996). The relationship between poverty and poor health appears to be recursive (Ruger, Jamison, \& Bloom, 2001; Wagstaff, 2002) such that the rich tend to be healthy and get richer and healthier while the poor tend to be less healthy and become poorer and less healthy; this cycle of poor health also plays out for the children of workers and managers, professionals, and executives, with longlasting health effects for the next generation. Differences in work stress, burnout, and absenteeism issues could be linked to worker status because of health differences associated with worker status; these health differences can both cause and be caused by worker status.

Some examples of how health is caused by worker status include handling of dangerous materials, being in riskier situations, and shiftwork. As noted above, workers are more likely to be exposed to the physically dangerous aspects of a job than are their managers (see Table 1). Shiftwork is typically assigned to workers rather than managers, professionals, and executives. Shiftwork is negatively associated with a number of negative health, safety, and well-being outcomes (Dinges, 1995; Harrington, 2001; Knutsson, 2003; C. S. Smith, Folkard, Tucker, \& Evans, 2010). In addition, the risk of work-related injury experienced by shift workers increases linearly from $18 \%$ from the morning shift to the afternoon shift and 30\% from the morning shift to the night shift, showing that those working the night shifts are most at risk for injury on the job (Folkard \& Tucker, 2003).

Health can also be caused by worker status rather than by exposure to health hazards at work (based on worker status). In a series of studies examining identity-based motivation and health, Oyserman, Fryberg, and Yoder (2007) found that racial/ethnic minority and low-SES participants perceived health promotion as being representative of the White middle class and not representative of their own in-group identity, and stronger in-group identity for these groups increased health fatalism and lowered access to health information. Thus, worker status could cause differences in engagement in health-promotion behavior, resulting in some employees (workers) being less healthy than other employees (managers, professionals, and executives).

In sum, the relationship between worker status and health demonstrates how human capital patterns and worker status reciprocally affect each other, experiences inside the organization, and experiences outside the organization. This further demonstrates the need to include more workers in our published studies in the I-O psychology literature. 


\section{Summary}

We have articulated four ways that the lack of representativeness of the labor market in the I-O psychology literature causes an impoverished science. First, we are likely to be overlooking phenomena that are important to workers but that are irrelevant to or uncommon in the lives of managers, professionals, and executives. Second, we could be misunderstanding the experiences of workers when they are studied because we have not adequately defined the phenomenon of interest relative to their experiences. Third, undersampling workers means that there is an important moderator-worker status-that is not being accounted for in the literature. Finally, there are other human capital patterns that are linked to worker status that could be important to understanding organizational functioning and individual wellbeing and performance. We do not claim that these are the only ways that our science is affected by the lack of workers in our studies, as there are likely to be other issues to consider. But these four seem to be important considerations as we move toward a critical understanding of the role of worker status in our field.

\section{Why Are Samples in the I-O Psychology Literature Skewed Toward Salaried and Professional Workers (and Students)?}

We have several suspicions as to why the published literature oversamples salaried and professional core employees (and students), to the detriment of studying workers. The following is meant to be an illustrative, not exhaustive, list of the reasons why workers are understudied.

\section{Computer-Based Surveying and Access to Computers}

One reason that managers, professionals, and executives (and students) are more likely to be included in studies is that they are easier to include in studies. Managers, professionals, and executives tend to have computers on their desks. Heck, they have desks! Although many workers have computers on their desks too (e.g., call center employees, secretaries), many do not (e.g., retail sales, food services, transport workers, construction workers). Employees who have easy access to computers throughout their workday are easier to recruit via e-mail to complete computer-delivered surveys during work hours. This resource makes this population very attractive in terms of access, response rate, and survey administration costs and time.

\section{Challenges With Multiple Stakeholders}

Another reason why workers might be understudied is that workers are more likely than are managers, professionals, and executives to be part of a labor union. Because of the tensions that often exist between corporate management and labor unions (Gill, 2009), it can be difficult to obtain buy-in and 
collaboration from all stakeholders relative to a study of workers. This might cause projects to be abandoned because the multiple stakeholders cannot come to an agreement or it might result in some employees (i.e., union members) not being included in some studies.

\section{Noncore Employees and Their Tenuous and Temporary Relationship With the Organization}

Noncore employees such as contractors, freelancers, and temps might not be registered with the organization's human resources or information technology departments, making it difficult to reach those people with e-mail invitations to participate in surveys. Even if they can be reached for the survey, contingent or temporary workers might not be associated with the organization through an entire multiwave survey period. Further, seasonal workers could be completely missed due to the timing of the research, even for crosssectional surveys.

Even if these workers can be reached via organizational channels, there might be reasons to exclude these workers from organization-sponsored surveys because excluding such workers reinforces their status as an organizational outsider and not a "true" employee. This is not meant to suggest that core employees are treating noncore employees badly; instead, the issue is that there are important legal reasons to ensure that people who are not organizational members are explicitly treated that way so that organizational benefits do not accrue to them (see "Don't Treat Contractors," 2009; Vizcaino v. Microsoft Corp., 1997).

\section{Pay Loss as Costs to the Organization}

Perceived organizational costs also play a role in studying salaried rather than hourly workers. It is easier to calculate the direct costs of wage earners' participation in surveys because they are paid for their time more so than for the completion of their work, the opposite of how salaried work is conceptualized. Further, hourly workers often either (a) are called into a survey session as a group or (b) need to arrange a time with their supervisors to leave their job tasks and take the survey. Each of these practices highlights for managers the direct costs of including wage earners in surveys. In contrast, salaried workers are not paid by the hour; they are paid for completing their work. Thus, a survey that impinges on 20 or 30 minutes of their time has little overall consequence relative to getting their work done over a day, week, or month.

\section{Organizational Biases}

Organizational biases also come into play. First, leadership theories often focus on alignment, strategy, and communication of goals from the 
strategic apex through management to the frontline workers (e.g., Bass \& Avolio, 1994; Kaiser, Hogan, \& Craig, 2008). This creates an assumptionstated or unstated - that fixing management will fix organizational problems, so studying management and managers is a good idea. This is obviously a mistake because alignment implies that all members of the organizationfrom top to bottom-have consistent goals and plans for achieving them. Examining alignment in only a subset of the organization undermines the defining feature of the construct. Assuming that first-line workers will simply fall in line because managerial ranks are aligned is folly.

An additional organizational bias arises from the organizational members who contract for a survey and who are unlikely to be workers. The ability to contract for an organizational survey usually resides within the managerial ranks, especially among those who are closer to the C-suite than the front line, because of their fiscal control and their responsibility for the direction and functioning of the organization. These organizational members will probably be concerned most about the issues that affect the people with whom they work most directly because memory biases (e.g., the availability heuristic) make those problems seem relatively common and because solving the problems of the people they work most closely with will result in fewer quotidian problems for the contracting member. Finally, related to the previous point, managers are likely to know something about organizational development and alignment and might fall into the erroneous assumption that fixing management will fix the organization.

\section{Researcher Biases}

Ongoing academic interest in leadership cannot alone account for the oversampling of managers, professionals, and executives relative to their workforce prevalence; other researcher biases are at play. Similar to organizational biases, researchers might believe that managers are more critical to organizational functioning than their sheer numbers suggest. As we noted above, there is some truth to this assertion because executives and managers are responsible for the overall direction of the organization and the execution of that vision in day-to-day operations, respectively. However, to understand the leadership system, it cannot be only leaders who are studied; the followers must be understood as well (Meindl, 1993).

Further, highly educated researchers-like those in I-O psychology, both academic and practice - might not recognize that the experiences of workers could be different from the experiences of managers, professionals, and executives. Research on the transmission of educational attainment and wealth across generations demonstrates that, on the average, PhDs in the social sciences have little experience within the worker ranks that are the focus of this article, either as workers themselves or as part of their families of origin 
(Bui, 2014; U.S. Department of Education, 2001). When researchers draw on their own experiences and observations to develop research questions, they might be unaware of the experiences of workers and have not considered what research questions are unasked about workers' experiences.

\section{What To Do?}

For the readers who believe that the underrepresentation of workers in the published I-O psychology literature is problematic, then the question quickly becomes this: How do we study workers more? Some solutions address this problem in terms of changing the methods we use as a science, whereas others address changing the practices of our scientific journals.

\section{Encourage Replication With Worker Samples}

Currently, the top journals in I-O psychology focus almost exclusively on novel science, with little interest in replication studies. For example, the description of Journal of Applied Psychology begins with "The Journal of Applied Psychology ${ }^{\circledR}$ emphasizes the publication of original investigations that contribute new knowledge and understanding to fields of applied psychology." Similarly, Personnel Psychology states that its publication purview is "original empirical research, theory development, meta-analytic reviews, and narrative literature reviews." Most of the top I-O psychology journals have similar statements in their descriptions, which tacitly exclude replication studies. This is shortsighted, as constructive replication in worker samples of phenomena that have been studied using manager, professional, or executive (or student) samples could illuminate important boundary conditions or demonstrate the universality of our theories and strengthen the argument that our theories are impactful.

It is clear in other fields (e.g., social psychology) that replication is becoming more important (Brandt et al., 2014; Nosek, Spies, \& Motyl, 2012; Pashler \& Harris, 2012), but published direct replications are extremely rare in psychology as a whole (Makel, Plucker, \& Hegarty, 2012). When direct replications are conducted but the result is contrary to the original findings, the results are reconciled to the file drawer (Pashler \& Harris, 2012). Perfect direct replications are nearly impossible to obtain because there must be differences in either time (using the same participants as the original study) or participants, and there can be differences in a variety of other factors (e.g., measures, methods; Brandt et al., 2014). Thus, replication where there are intentional departures from the original study-such as changes in the population from which the sample is drawn-necessitates greater consistency between the original study and the replicating study for the other methodological factors in order to test (a) the replicability of the original result and (b) the generalizability to other populations. 
Of course, conceptual replication occurs in I-O psychology because meta-analyses could not be conducted otherwise. However, I-O psychology's penchant for meta-analysis actually compounds many of the problems discussed herein because the population correlations derived from the metaanalysis of sample correlations applies to only the specific population from which the sample was derived and not the population of the world. Although meta-analysts are clear about this issue, there is little critical analysis about who that population is in most published meta-analyses. Thus, it is easy to misinterpret and misreport the population statistic as the truth for the entire populace and to assume that there would be no differences in other parts of the labor market because of failsafe $N$ calculations and similar indices. Although inclusion of worker samples would probably not make the population $r$ equal zero, including worker samples could considerably change the population correlation estimate as well as indicate an important moderator. Without sufficient primary studies that draw on these samples, there is no way to test for the moderation of effects that could occur by this factor.

Thus, one way forward is to change the culture at our top journals from a tight focus on novel tests of theory to include more replication of the journals' own publications. These replications could be published with little theoretical development beyond a basic review of the original article's tenets. Such a movement among our journals would advance our science considerably by (a) demonstrating the stability of our findings across time, samples, and settings; (b) illuminating where there are boundary conditions, spurring further research; (c) translating our theoretical work into reports of practical use and insights from applied scientists in the field; and (d) bridging the academic-practice divide.

\section{Sample Workers Using Different Strategies}

As previously mentioned, there are a number of reasons that studying workers is more difficult than studying undergraduates, professionals, managers, and executives. Although technology has solved some access problems, it may still be necessary to study workers via paper-and-pencil methods. This might be necessary because of the demands on organizational scheduling or union oversight (e.g., it might be necessary to survey many people at a single time-such as during the morning meeting before a shift begins maintenance work at a utility plant). Worker trust might also be higher in paper-and-pencil methods, as it is incredibly difficult to identify who filled out which paper survey unless names or other identifiers are added.

Internet panel services offer a good alternative to surveying workers during the workday at their work organization. Internet panel companies allow researchers to select inclusion criteria. Because survey takers on some Internet panel services (Ipeirotis, 2010) have lower average household incomes 
than the whole United States Internet population does, it is likely that there are many workers relative to salaried professionals and managers available for participation.

Workers could also be accessed through trade groups. Because all of the members are engaged in the same trade, the work qualifications would be held relatively constant. Instead, workers would differ on work arrangements (e.g., salaried vs. wage earner; contingent or contract workers vs. core workers; Hulin \& Glomb, 1999), allowing for a deeper understanding of how work arrangements influence workplace attitudes, well-being, and behavior. In addition, trade groups might be a particularly good way of reaching seasonal or itinerant workers (e.g., construction crew) or workers who are on contract, freelance, or have another external relationship with employing organizations. Although trade group samples might be biased relative to the population of workers (i.e., these workers might differ in systematic ways from workers who do not belong to such groups), it is unknown whether this is a worse bias for the published I-O literature than excluding workers altogether. Our guess is that it is better for the development of the I-O science regarding workers' experiences to include workers from trade groups than to not include workers at all.

Further, workers could be contacted via their neighborhoods, at least in urban settings in the United States and probably in many other locations in the United States and around the world. Because property values tend to be clustered, such that expensive homes are near other expensive homes and inexpensive housing is near inexpensive housing, it is likely that people who make less money will be found in neighborhoods where people live in less expensive housing, and workers generally make less money than managers, professionals, and executives do. Contacting potential participants by home location is not common in I-O psychology, but there are ample examples in health-related and sociology research.

\section{Be Open to Qualitative Work}

It might be necessary to first observe and qualitatively study workers to determine what issues they encounter in the workplace. Qualitatively studying a novel phenomenon is a necessary first step to understanding it before quantitatively studying what you determine to be important variables comprising and surrounding the phenomenon. It may be the case that we don't know how to study workers because we don't know what unique challenges they face and because we don't view the world from their perspective. Qualitative investigation would be a useful tool to learn more about workers' perceptions of the organization and about how to best study and communicate with workers about organizational issues that impact their work lives and the organizations in which they work. 


\section{Conclusion}

Where have all the workers gone? It is clear that they have not gone anywhere from organizations and the world of working, but they have not appeared in our published scientific literature at a rate proportional to their representation in the labor market. We have argued that this does a disservice to our field and to these people by drawing a biased understanding of the experiences of employed persons due to disproportional sampling and by failing to study questions that are critical to workers but not to managers, professionals, and executives. Moving forward, we encourage everyone engaged in I-O psychology to ask themselves about workers and their experiences and to expand their samples and studies to include this important and large part of the employee base. Doing so will develop more comprehensive theories and a greater number of generalizable findings. It is our duty as scientists to provide research that organizations and society can use for the betterment of all employees. This article identifies ways in which we can begin conquering this issue. It is our hope that our efforts will serve as a call to action to researchers, reviewers, and editors to expect more representation of the entire labor market in our studies in order to understand and benefit all.

\section{References}

Adams, G., \& Salter, P. (2011). A critical race psychology is not yet born. Connecticut Law Review, 43, 1355-1377.

Adler, N. E., \& Rehkopf, D. H. (2008). U.S. disparities in health: Descriptions, causes, and mechanisms. Annual Review of Public Health, 29, 235-252.

Alaimo, K., Olson, C. M., \& Frongillo, E. A., Jr. (2001). Food insufficiency and American school-aged children's cognitive, academic, and psychosocial development. Pediatrics, $108,44-53$.

Allen, T. (2013). President's column. The Industrial Psychologist, 51(1), 5-7.

Aronsson, G., \& Gustafsson, K. (2005). Sickness presenteeism: Prevalence, attendancepressure factors, and an outline of a model for research. Journal of Occupational and Environmental Medicine, 47, 958-966.

Aronsson, G., Gustafsson, K., \& Dallner, M. (2000). Sick but at work. An empirical study of sickness presenteeism. Journal of Epidemiology and Community Health, 54, 502-509.

Ashford, S., Lee, C., \& Bobko, P. (1989). Content, causes, and consequences of job insecurity: A theory-based measure and substantive test. Academy of Management Journal, 32, 803-829.

Bass, B. M., \& Avolio, B. J. (1994). Improving organizational effectiveness through transformational leadership. Thousand Oaks, CA: Sage.

Beal, D. J., Trougakos, J. P., Weiss, H. M., \& Green, S. G. (2006). Episodic processes in emotional labor: Perceptions of affective delivery and regulation strategies. Journal of Applied Psychology, 91, 1053-1065.

Berglund, T., Furaker, B., \& Vulkan, P. (2014). Is job insecurity compensated for by employment and income security? Economic and Industrial Democracy, 35, 165-184. 
Beus, J. M., Jarrett, S., Bergman, M. E., \& Payne, S. C. (2010, April). Safety climate perceptions across the organizational hierarchy. Poster presented at the 25th Annual Conference of the Society for Industrial and Organizational Psychology, Atlanta, GA.

Bohan, J. S. (1993). Regarding gender: Essentialism, constructionism, and feminist psychology. Psychology of Women Quarterly, 17, 5-21.

Boyd, E. M., \& Sliter, M. T. (2014). Two (or three) is not equal to one: Multiple jobholding as a neglected topic in organizational research. Journal of Organizational Behavior, 35 , 1042-1046.

Brandt, M. J., IJzerman, H., Dijksterhuis, A., Farach, F. J., Geller, J., Giner-Sorolla, R., . . . Van't Veer, A. (2014). The replication recipe: What makes for a convincing replication? Journal of Experimental Social Psychology, 50, 217-224.

Brooks-Gunn, J., \& Duncan, G. J. (1997). The effects of poverty on children. The Future of Children, 7, 55-71.

Bui, Q. (2014, March 18). Who had richer parents, doctors or artists? [Web log post]. Retrieved from http://www.npr.org/blogs/money/2014/03/18/289013884/who-hadricher-parents-doctors-or-artists

Bureau of Labor Statistics. (2013). Median weekly earnings of full-time wage and salary workers by detailed occupation and sex. Retrieved from http://www.bls.gov/cps/cpsaat39.pdf

Bureau of Labor Statistics. (2015a). Occupational employment and wages-May 2014. Retrieved from http://www.bls.gov/news.release/pdf/ocwage.pdf

Bureau of Labor Statistics. (2015b). Table A-5: Fatal occupational injuries by occupation and event or exposure, all United States, 2013. Retrieved from http:// www.bls.gov/iif/oshwc/cfoi/cftb0281.pdf

Campbell, J. P. (1990). The role of theory in industrial and organizational psychology. In M. D. Dunnette \& L. M. Hough (Eds.), Handbook of industrial and organizational psychology (pp. 39-73). Palo Alto, CA: Consulting Psychologists Press.

Canales, M. K. (2000). Othering: Toward an understanding of difference. Advances in Nursing Science, 22, 16-31.

Cheyne, A., Tomas, J. M., Cox, S., \& Oliver, A. (2003). Perceptions of safety climate at different employment levels. Work \& Stress: An International Journal of Work, Health \& Organisations, 17, 21-37.

Cox, T., \& Cox, S. (1993). Occupational health: Control and monitoring of psychosocial and organizational hazards at work. Perspectives in Public Health, 113, 201205.

Dalal, R. S., Bonaccio, S., Highhouse, S., Ilgen, D. R., Mohammed, S., \& Slaughter, J. E. (2010). What if industrial-organizational psychology decided to take workplace decisions seriously? Industrial and Organizational Psychology, 3, 386-405.

Dill, K. (2014, September 25). America's 10 deadliest jobs. Forbes [online]. Retrieved from http://www.forbes.com/sites/kathryndill/2014/09/25/americas-10-deadliest-jobs/

Dinges, D. F. (1995). An overview of sleepiness and accidents. Journal of Sleep Research, 4, 4-14.

Don't treat contractors like employees. (2009, April 1). Retrieved from http:// www.reuters.com

Dowling, G. R. (2001). The alpha, beta, gamma approach to measuring change and its use for interpreting the effectiveness of service quality programs. Australian Journal of Management, 26, 55-67.

Fair Labor Standards Act of 1938, as amended, $\$ 29$ U.S.C. 201 et seq. (2011).

Feldman, D. C. (1990). Reconceptualizing the nature and consequences of part-time work. Academy of Management Review, 15, 103-112. 
Fitzgerald, L. F., Hulin, C. L., \& Drasgow, F. (1995). The antecedents and consequences of sexual harassment in organizations: An integrated model. In G. Keita \& J. Hurrell Jr. (Eds.), Job stress in a changing workforce: Investigating gender, diversity, and family issues (pp. 55-73). Washington, DC: American Psychological Association.

Folkard, S., \& Tucker, P. (2003). Shift work, safety, and productivity. Occupational Medicine, 53, 95-101.

Fox, D., Prilleltensky, I., \& Austin, S. (Eds.). (2009). Critical psychology: An introduction (2nd ed.). London, United Kingdom: Sage.

Gill, C. (2009). Union impact of the effective adoption of high performance work practices. Human Resource Management Review, 19, 39-50.

Gulf Research Program. (2014). Opportunities for the Gulf Research Program: Middle-skilled workforce needs: Summary of a workshop. Washington, DC: The National Academies Press.

Harrington, J. M. (1994). Shift work and health-A critical review of the literature on working hours. Annals of the Academy of Medicine Singapore, 23, 699-705.

Harrington, J. M. (2001). Health effects of shift work and extended hours of work. Occupational \& Environmental Medicine, 58, 68-72. doi:10.1136/oem.58.1.68

Harris, A. P. (1990). Race and essentialism in feminist legal theory. Stanford Law Review, 42, 581-616.

Harvey, J., Bolam, H., \& Gregory, D. (1999). How many safety cultures are there? The Safety and Health Practitioner, 17, 8-12.

Henrich, J., Heine, S. J., \& Norenzayan, A. (2010). The weirdest people in the world? Behavioral and Brain Sciences, 33, 61-83.

Henry, P. J. (2008). College sophomores in the laboratory redux: Influences of a narrow data base on social psychology's view of the nature of prejudice. Psychological Inquiry, 19, 49-71.

Hill, E. J., Erickson, J. J., Holmes, E. K., \& Ferris, M. (2010). Workplace flexibility, work hours, and work-life conflict: Finding an extra day or two. Journal of Family Psychology, 24, 349-358.

Howard, J. S., Mattacola, C. G., Howell, D. M., \& Lattermann, C. (2011). Response shift theory: An application for health-related quality of life in rehabilitation research and practice. Journal of Allied Health, 40, 31-38.

Hulin, C. L. (1991). Adaptation, persistence, and commitment in organizations. In M. D. Dunnette \& L. M. Hough (Eds.), Handbook of industrial and organizational psychology (Vol. 2, pp. 445-505). Palo Alto, CA: Consulting Psychologists Press.

Hulin, C. L., \& Glomb, T. M. (1999). Contingent employees: Individual and organizational considerations. In D. Ilgen \& E. Pulakos (Eds.), The changing nature of work performance: Implications for staffing, personnel actions, and development (pp. 87-118). San Francisco, CA: Josey Bass.

Hunter, J. E. (1986). Cognitive ability, cognitive aptitudes, job knowledge. Journal of Vocational Behavior, 29, 340-362.

Ilgen, D. R. (1985). Laboratory research: A question of when, not if. In E. A. Locke (Ed.), The generalizability of laboratory experiments: An inductive survey (pp. 257-267). Lexington, MA: D. C. Heath.

International Labour Organization. (2014). KILM 5. Employment by occupation. Retrieved from http://kilm.ilo.org/2011/download/kilm05EN.pdf

Ipeirotis, P. (2010). Demographics of Mechanical Turk. Retrieved from http:// hdl.handle.net/2451/29585 
Jacobs, A. W., \& Padavic, I. (2014). Hours, scheduling and flexibility for women in the U.S. low-wage labour force. Gender, Work and Organization, 22, 67-86.

Jamal, M., Baba, V., \& Riviére, R. (1998). Job stress and well-being of moonlighters: The perspective of deprivation or aspiration revisited. Stress and Health, 14, 195-202.

Johnson, J. V., \& Lipscomb, J. (2006). Long working hours, occupational health, and the changing nature of work organization. American Journal of Industrial Medicine, 49, 921-929.

Kaiser, R. B., Hogan, R., \& Craig, S. B. (2008). Leadership and the fate of organizations. American Psychologist, 63, 96-110.

Kammeyer-Mueller, J. D., Rubenstein, A. L., Long, D. M., Odio, M. A., Buckman, B. R., Zhang, Y., \& Halvorsen-Ganepola, M. D. K. (2013). A meta-analytic structural model of dispositional affectivity and emotional labor. Personnel Psychology, 66, 47-90.

Knutsson, A. (2003). Health disorders of shift workers. Occupational Medicine, 53, 103-108. doi:10.1093/occmed/kqg048

Lambert, S. J., Haley-Lock, A., \& Henly, J. R. (2012). Schedule flexibility in hourly jobs: Unanticipated consequences and promising directions. Community, Work and Family, 15, 293-315.

Landsberger, H. A. (1958). Hawthorne revisited: Management and the worker: Its critics, and development in human relations in industry. Ithaca, NY: Cornell University.

Lee, T. W., \& Mitchell, T. R. (1994). An alternative approach: The unfolding model of voluntary employee turnover. Academy of Management Review, 19, 51-89.

Makel, M. C., Plucker, J. A., \& Hegarty, B. (2012). Replications in psychology research: How often do they really occur? Perspectives on Psychological Science, 7, 537-542.

McMenamen, T. M. (2007, December). A time to work: Recent trends in shift work and flexible schedules. Monthly Labor Review, 130, 3-15.

Meindl, J. R. (1993). Reinventing leadership: A radical, social psychological approach. In J. K. Munighan (Ed.), Social psychology in organizations (pp. 89-118). Englewood Cliffs, NJ: Prentice-Hall.

Mintzberg, H. (1980). Structure in 5's: A synthesis of the research on organization design. Management Science, 26, 322-341.

National Science Board. (2012). Science and engineering indicators 2012 (NSB 12-01). Arlington, VA: National Science Foundation.

Nosek, B. A., Spies, J. R., \& Motyl, M. (2012). Scientific utopia II. Restructuring incentives and practices to promote truth over publishability. Perspectives on Psychological Science, $7(6), 615-631$.

Organisation for Economic Co-operation and Development. (n.d.). About the OECDWhat is the OECD? Retrieved from http://usoecd.usmission.gov/mission/ overview.html

Oyserman, D., Fryberg, S. A., \& Yoder, N. (2007). Identity-based motivation and health. Journal of Personality and Social Psychology, 93, 1011-1027.

Pashler, H., \& Harris, C. R. (2012). Is the replicability crisis overblown? Three arguments examined. Perspectives on Psychological Science, 7(6), 531-536.

Pritchett, L., \& Summers, L. H. (1996). Wealthier is healthier. Journal of Human Resources, $31,841-868$.

Probst, T. M. (2000). Wedded to the job: Moderating effects of job involvement on the consequences of job insecurity. Journal of Occupational Health Psychology, 5, 6373.

Reynolds, D. (2012). A message from your president. The Industrial Psychologist, 50(1), 711. 
Robie, C., Ryan, A. M., Schmieder, R. A., Parra, L. F., \& Smith, P. C. (1998). The relation between job level and job satisfaction. Group \& Organization Management, 23, 470495. doi:10.1177/1059601198234007

Rotchford, N. L., \& Roberts, K. H. (1982). Part time workers as missing persons in organizational research. Academy of Management Review, 7, 228-234.

Ruger, J. P., Jamison, D. T., \& Bloom, D. E. (2001). Health and the economy. In M. H Merson, R. E. Black, \& A. J. Mills (Eds.), International public health (pp. 617-666). Gaithersburg, MD: Aspen.

Ryan, A. M., \& Ford, J. K. (2010). Organizational psychology and the tipping point of professional identity. Industrial and Organizational Psychology: Perspectives on Science and Practice, 3, 241-258.

Salter, P., \& Adams, G. (2013). Toward a critical race psychology. Social and Personality Psychology Compass, 7, 781-793.

Scandura, T. A., \& Lankau, M. J. (1997). Relationships of gender, family responsibility and flexible work hours to organizational commitment and job satisfaction. Journal of Organizational Behavior, 18, 377-391.

Sears, D. O. (1986). College sophomores in the lab: Influences of a narrow data base on social psychology's view of human nature. Journal of Personality and Social Psychology, 51, 515-530.

Shockley, K. M., \& Allen, T. D. (2007). When flexibility helps: Another look at the availability of flexible work arrangement and work-family conflict. Journal of Vocational Behavior, 71, 479-493.

Smith, C. S., Folkard, S., Tucker, P., \& Evans, M. S. (2010). Work schedules, health, and safety. In L. E. Tetrick \& J. C. Quick (Eds.), Handbook of occupational health psychology (2nd ed., pp. 185-204). Washington, DC: American Psychological Association.

Smith, P. C., Kendall, L. M., \& Hulin, C. L. (1969). The measurement of satisfaction at work and retirement: A strategy for the study of attitudes. Chicago, IL: Rand McNally.

Sue, S. (1999). Science, ethnicity, and bias: Where have we gone wrong? American Psychologist, 54, 1070-1077.

Thibaut, J. W., \& Kelley, H. H. (1959). The social psychology of groups. New York, NY: Wiley.

Tversky, A., \& Kahneman, D. (1973). Availability: A heuristic for judging frequency and probability. Cognitive Psychology, 5, 207-232.

U.S. Department of Education, National Center for Education Statistics. (2001). The condition of education 2001 (NCES Report 2001-072). Washington, DC: U.S. Government Printing Office.

Vizcaino v. Microsoft Corp., 120 F.3d 1006 (9th Cir. 1997).

Wagstaff, A. (2002). Poverty and health sector inequalities. Bulletin of the World Health Organization, 80, 97-105.

Weis, L. (1995). Identity formation and the processes of "othering": Unraveling sexual threads. Educational Foundations, 9(1), 17-33.

Williams, C. L. (2006). Inside toyland: Working, shopping, and social inequality. Berkeley, CA: University of California Press.

World Statistics. (n.d.). Employment by occupation. Retrieved from http://worldstatistics.org/result.php?code = KILM.ISCO08.MF?name $=$ Employment\%20by\%20 occupation, $\% 20$ total\%20(\%\%20of\%20total\%20employment, $\% 20$ ISCO08

Zickar, M., Gibby, R., \& Jenny, T. (2004). Job attitudes of workers with two jobs. Journal of Vocational Behavior, 64, 222-235. 
Zohar, D. (2010). Thirty years of safety climate research: Reflections and future directions. Accident Analysis and Prevention, 42, 1517-1522.

Zohar, D. (2014). Safety climate: Conceptualization, measurement, and improvement. In B. Schneider \& K. M. Barbera (Eds.), The Oxford handbook of organizational climate and culture (pp. 317-334). New York, NY: Oxford. 